\title{
PRECIPITAÇÃO EFETIVA EM DIFERENTES FORMAÇÕES FLORESTAIS NA FLORESTA NACIONAL DE IPANEMA ${ }^{1}$
}

Kelly Cristina Tonello², Esthevan Augusto Goes Gasparoto ${ }^{3}$, Emily Tsiemi Shinzato ${ }^{4}$, Roberta de oliveira Averna Valente ${ }^{2}$ e Herly Carlos Teixeira Dias ${ }^{5}$

\begin{abstract}
RESUMO - O presente trabalho foi conduzido na Floresta Nacional de Ipanema, unidade de conservação de uso sustentável localizada no município de Iperó-SP, com o objetivo de quantificar e comparar as frações de precipitação efetiva e interceptação da chuva em três povoamentos florestais distintos, sendo eles: Eucalyptus cloeziana, Pinus caribea var. hondurensis e Floresta Estacional Semidecidual. Para tanto, realizou-se o monitoramento das variáveis precipitação interna, escoamento pelo tronco, interceptação e precipitação em aberto em cada formação florestal, ao longo do período de novembro de 2009 à maio de 2010. O estudo revelou a precipitação efetiva de $86,2 \%, 85,0 \%$ e 77,2\%; interceptação de 13,8\%, 15,0\% e 22,8\% em relação à precipitação em aberto em Eucalyptus cloeziana, Pinus caribea var. hondurensis e Floresta Estacional Semidecidual, respectivamente. A influência dos povoamentos na distribuição da chuva apresentou diferença significativa somente para o processo de interceptação entre Floresta Estacional Semidecidual e os demais.
\end{abstract}

Palavras-chave: Precipitação interna; Escoamento pelo tronco; Hidrologia florestal.

\section{NET PRECIPITATION IN DIFFERENT FOREST FRAGMENTS OF IPANEMA NATIONAL FOREST}

\begin{abstract}
This study was conducted in the National Forest of Ipanema, sustainable conservation in the municipality of Iperó-SP, in order to quantify and compare the net precipitation and interception of rain in three different forest stands, which are: Eucalyptus cloeziana, Pinus caribea var. hondurensis and Floresta Estacional Semidecidual. Therefore, we carried out the monitoring of throughfall, stemflow, interception and gross precipitation in each forest type, over the period November 2009 to May 2010. The study revealed the throughfall of $86.2 \%, 85.0 \%$ and $77.2 \%$; intercept of $13.8 \%, 15.0 \%$ and $22.8 \%$ in relation to gross precipitation in Eucalyptus cloeziana, Pinus caribea var. hondurensis and Floresta Estacional Semidecidual, respectively. The influence of the forests in the distribution of precipitation showed significant difference only for the process of interception between Floresta Estacional Semidecidual and others.
\end{abstract}

Keywords: Throughfall; Stemflow; Forest Hidrology.

\footnotetext{
${ }^{1}$ Recebido em 01.04.2012 aceito para publicação em 13.02.2014.

${ }^{2}$ Departamento de Ciências Ambientais, Universidade Federal de São Carlos, campus Sorocaba, UFSCAR, Brasil. E-mail: <kellytonello@ufscar.br>e<roavalen@ufscar.br>.

${ }^{3}$ Departamento de Ciências Florestais, Escola Superior de Agricultura "Luiz de Queiroz", ESALQ/USP, Brasil. <esthevan@florestal.eng.br ${ }^{4}$ Departamento de Sensoriamento Remoto , Instituto de Pesquisas Espaciais, INPE, Brasil. <emilyshinzato@florestal.eng.br>

${ }^{5}$ Universidade Federal de Viçosa, Departamento de Engenharia Florestal,UFV, Brasil. E-mail: <herly@ufv.br>.
} 


\section{INTRODUÇÃO}

A precipitação é definida na hidrologia como toda água proveniente do meio atmosférico, em qualquer estado físico, que atinge a superfície terrestre. Sendo a chuva o tipo de precipitação mais importante para a hidrologia e suas ramificações. À medida que se aproxima da superfície, a chuva pode ser interceptada por diversos tipos de barreiras, sendo a cobertura florestal a de maior importância, pois permite que a parte das chuvas que percola o dossel florestal, possa atingir a superfície do solo com menor impacto. À esta fração das chuvas, que atinge o solo, denomina-se precipitação efetiva (Pe), podendo ser dividida em duas frações, a precipitação interna $(\mathrm{Pi})$ e escoamento pelo tronco (Et) (KLASSEN et al., 1996).

A precipitação interna consiste na chuva que atravessa o dossel das florestas, o que inclui as gotas que passam diretamente pelas aberturas entre as copas e as gotas que respingam do dossel (OLIVEIRA JÚNIOR; DIAS, 2005). Já o escoamento pelo tronco equivale à água da chuva que, após ser retida pela copa, escoa pelos galhos e troncos em direção ao solo. Para que o escoamento pelo tronco ocorra, é preciso primeiro que aconteça a saturação da copa, isto é, seja atingida a sua capacidade máxima de retenção de água, e dada a continuidade da chuva, inicia-se então o processo de escoamento pelo tronco. Logo, em um evento de chuva, toda a água que não é convertida em forma de precipitação efetiva, fica retida nas copas, caracterizando o processo de interceptação.

Segundo Lima (1993), a interceptação da água das chuvas como componente do balanço hídrico, em regiões de regime de chuvas leves, porém contínuas e freqüentes, pode representar a maior parcela do consumo total de água por uma floresta, suplantando a transpiração pelas árvores.

Jiménez et al. (1996), reforçam ainda que o conhecimento do tamanho de cada uma das três frações na partição das chuvas, interceptação, precipitação interna e escoamento pelo tronco, é um complemento indispensável para se obter valor preciso do balanço hídrico em uma floresta, sendo imprescindível o conhecimento da participação da interceptação no processo de evapotranspiração.

Leopoldo e Conte (1985), salientam que a precipitação efetiva e a interceptação assumem importante papel no estudo dos processos de infiltração, percolação, absorção, transpiração e ciclagem de nutrientes em ecossistemas florestais, e que a quantidade de água das variáveis envolvidas na precipitação efetiva, depende de fatores relacionados tanto à vegetação quanto a condições climáticas nas quais a floresta está inserida. Além disso, fatores experimentais podem também influenciar nos resultados obtidos dos estudos destes processos, dificultando a comparação de resultados entre diferentes locais (CASTRO et al., 1983).

A Floresta Nacional de Ipanema (FLONA Ipanema) é uma unidade de conservação sustentável, possuindo em sua propriedade áreas de floresta nativa em diferentes estágios sucessionais, além de plantios de espécies exóticas como Eucalyptus sp e Pinus caribea var. hondurensis. Essa facilidade de se ter em um mesmo local três formações florestais distintas e vizinhas motivaram a realização deste estudo.

Nesse sentido, de modo a eliminar variações ambientais como altitude, latitude, temperatura e clima, bem como diferenças metodológicas entre diferentes estudos, o presente trabalho tem por objetivo quantificar e comparar as frações de precipitação efetiva e interceptação em três formações florestais vizinhas de Eucalyptus cloeziana, Pinus caribea var. hondurensis e Floresta Estacional Semidecidual, na Floresta Nacional de Ipanema, em Iperó, SP.

\section{MATERIAL E MÉTODOS}

\subsection{Caracterização da área de estudo}

O presente estudo foi conduzido na Floresta Nacional de Ipanema (FLONA Ipanema), localizada no município de Iperó-SP, entre as coordenadas $23^{\circ} 25^{\prime}$ e $23^{\circ} 27^{\prime} \mathrm{S}$, $47^{\circ} 35^{\prime}$ e $47^{\circ} 40^{\prime} \mathrm{O}$, e altitudes entre $550 \mathrm{~m}$ a $968 \mathrm{~m}$ (REGALADO, 1999).

De acordo com a classificação de Köppen, o clima da região é do tipo “Cfa”, denominado como subtropical mesotérmico úmido, sem estiagens, com estações chuvosas e secas bem definidas (Albuquerque, 1999) e precipitação média anual de 1.400 mm (SOUZA; MARTOS, 2008). Segundo Radambrasil (1984), a vegetação da FLONA Ipanema é caracterizada como área de transição entre diferentes ecossistemas, possuindo como principais formações vegetais a Floresta Estacional Semidecidual, o Cerrado e a Floresta Ombrófila Densa, além de Eucalyptus sp e Pinus caribea var. hondurensis. 


\subsection{Implantação e variáveis hidrológicas}

Por ser tratar de uma unidade de conservação de uso sustentável, a Flona Ipanema apresenta uma diversidade de formações florestais em sua área e esse estudo buscou aproveitar a oportunidade em se ter talhões de Pinus caribea var. hondurensis (12 anos de idade), Eucalyptus cloeziana (15 anos de idade) e Floresta Estacional Semidecidual secundária (estimativa de 35 anos de idade) vizinhos (500 m de distância entre eles). As três formações florestais monitoradas encontram-se em terreno de topografia plana (1\% de declividade) localizadas entre os paralelos $23^{\circ} 25^{\prime} \mathrm{S}$ e $26^{\circ} 23^{\prime} \mathrm{S}$ e meridianos $47^{\circ} 35^{\prime} \mathrm{O}$ e $47^{\circ} 35^{\prime} \mathrm{O}$.

Ao longo do período de novembro de 2009 e maio de 2010 realizou-se o monitoramento das variáveis hidrológicas: precipitação em aberto, escoamento pelo tronco e precipitação interna, assim como o levantamento de características da vegetação que possuem influência sobre essas determinações.

De modo a identificar diferenças na partição de chuva entre os três povoamentos florestais, os dados de precipitação efetiva (PE) e interceptação (I) foram analisados estatisticamente, utilizando a análise de variância e a comparação das médias pelo teste Tukey $(\mathrm{P}<0,05)$. O delineamento experimental utilizado foi o inteiramente casualizado, considerando-se como tratamento as formações florestais e em cada uma delas, 10 árvores foram escolhidas aleatoriamente (unidades amostrais) e monitoradas em 25 eventos de chuva.

\subsubsection{Precipitação em aberto}

De forma a obter maior precisão no monitoramento da precipitação em aberto (P), foram instalados 3 pluviômetros próximos a cada formação florestal, a 1,5 m da superfície do terreno, tendo-se o cuidado de eliminar qualquer barreira que influenciasse a captação de água da chuva. O cálculo da precipitação em aberto foi obtido pela média aritmética dos pluviômetros a partir da seguinte equação:

$$
P=(V / A) * 10
$$

sendo, $\mathrm{P}$ a precipitação em aberto (mm), V o volume do pluviômetro (ml) e A a área de captação do pluviômetro $\left(\mathrm{cm}^{2}\right)$.

\subsubsection{Escoamento pelo tronco}

Para a quantificação do escoamento pelo tronco, foram selecionadas 10 árvores com circunferência altura do peito (CAP) $\geq 15 \mathrm{~cm}$, as quais foram envolvidas por uma calha confeccionada a partir de borracha, com a função de conduzir a água escoada pelos troncos para coletores de 20 litros.

Uma vez que o escoamento pelo tronco está relacionado, dentre outros fatores, com a área foliar do estrato arbóreo, buscou-se a determinação da área das copas das árvores selecionadas por meio da projeção vertical de cada copa no solo. Para isso, seccionou-se a mesma em 8 direções, com ângulos de $45^{\circ}$ entre si, a partir do centro do tronco até a extremidade da projeção da copa, conforme metodologia proposta por Moura et al. (2009). Para o cálculo da área de cada copa utilizou-se a seguinte equação:

$$
\mathrm{A}=\Sigma \frac{a^{*} b^{*} \operatorname{sen} 45^{\circ}}{2}
$$

sendo, A a somatória das áreas de cada secção em $\mathrm{m}^{2}$, a e b os comprimentos em metros de duas secções em um ângulo de $45^{\circ}$ entre si.

Dessa forma, o escoamento pelo tronco foi determinado como:

$$
E t=(V / A)
$$

sendo, Et o escoamento pelo tronco ( $\mathrm{mm}), \mathrm{V}$ o volume do coletor em litros (L) e A a área estimada da copa $\left(\mathrm{m}^{2}\right)$.

\subsubsection{Precipitação interna}

No interior de cada formação florestal foram instalados 10 coletores próximos às árvores selecionadas para monitoramento da $\mathrm{Pi}$. Os coletores foram confeccionados a partir de garrafas plásticas com capacidade de armazenamento de 5 e 10 litros, munidas de funis de captação para recepção da água de chuva, instalados à 0,50 m de altura em relação ao solo. Desse modo, a precipitação interna armazenada nos coletores foi obtida por:

$$
P i=(V / A) * 10
$$

sendo, Pi a precipitação interna (mm), V o volume de cada coletor (ml) e A a área de captação de cada coletor $\left(\mathrm{cm}^{2}\right)$.

Revista Árvore, Viçosa-MG, v.38, n.2, p.383-390, 2014 


\subsubsection{Precipitação efetiva}

Corresponde ao somatório da água escoada pelos troncos e a precipitação interna em cada formação florestal (Equação 5).

$$
P e=P i+E t
$$

sendo, PE a precipitação efetiva (mm), Pi a precipitação interna (mm) e Et o escoamento pelo tronco (mm).

\subsubsection{Interceptação}

Obtida a partir da diferença entre a precipitação em aberto e a precipitação efetiva em cada formação florestal (Equação 6).

$$
I=P-P e
$$

sendo, I a interceptação (mm), P a precipitação em aberto $(\mathrm{mm})$ e Pe a precipitação efetiva $(\mathrm{mm})$.

\subsection{Cobertura foliar}

Para cada formação florestal foi determinada a cobertura foliar (CF\%) acima do solo por meio de cinco imagens digitais obtidas a partir de pontos próximos aos coletores por meio de uma câmera digital semiprofissional Sony DSC-H5, sobre um tripé a 50 cm do solo (mesma altura do bocal de captação de água dos coletores de $\mathrm{Pi}$ ). Todas as imagens foram obtidas sempre no modo automático (Monte et al., 2007), à distância focal mínima do equipamento de $6 \mathrm{~mm}$, o quê corresponde à distância focal equivalente de $36 \mathrm{~mm}$ em máquinas de 35mm.

Posteriormente, as imagens foram recortadas, sendo aproveitados apenas 25\% da área total, referentes à porção central das mesmas. Em seguida as imagens foram submetidas ao software de processamento de imagens IDRISI Andes, onde foram reclassificadas em escala de cinza e posteriormente tiveram seus pixels quantificados em um histograma com o intuito de quantificar a porcentagem de pixels das mesmas, por meio da interpretação visual, que representariam a cobertura vegetal e a porcentagem de pixels que representam espaços livres (sem folhas, galhos e troncos), por onde a água possa atravessar sem barreiras o dossel florestal. A média das porcentagens das cinco imagens representou então, a porcentagem de cobertura que as copas exercem acima do solo (Figura 1).

\section{RESULTADOS}

Durante o período de monitoramento foram registrados 25 eventos de chuva assim como sua respectiva partição entre precipitação efetiva (Pe) e interceptação (I) nas formações florestais de E. cloeziana, $P$. caribea var. hondurensis e Floresta Estacional Semidecidual (Tabela 1). Observou-se que ao longo do período de avaliação, a precipitação em aberto (P) diferiu entre as formações florestais: E. cloeziana registrou-se o total de 520,4 mm; P. caribea var. hondurensis, 499,3 $\mathrm{mm}$ e na Floresta Estacional Semidecidual, 540,1 mm, correspondendo à aproximadamente $37 \%$ da precipitação média anual da região.

A maior contribuição para a precipitação efetiva foi observada para E. cloeziana com $86,2 \%$ da precipitação em aberto, onde a precipitação interna e o escoamento pelo tronco corresponderam a $85,2 \%$ e 1,0\%, respectivamente. Em contrapartida, a Floresta Estacional Semidecidual apresentou os menores valores de precipitação efetiva, com 77,2\% da precipitação em aberto, distribuída em 76,2\% de precipitação interna e $1,0 \%$ de escoamento pelo tronco e por conseqüência, a maior perda por interceptação ( $(=22,8 \%)$ quando comparada à E. cloeziana (13,8\%) e P. caribea var. hondurensis (15,0\%). Estatisticamente não foram observadas diferenças na precipitação efetiva entre as formações florestais. Entretanto, o mesmo não ocorreu para a interceptação quando realizada a análise de variância. $\mathrm{O}$ teste de Tukey $(\mathrm{P}<0,05)$ apontou uma maior
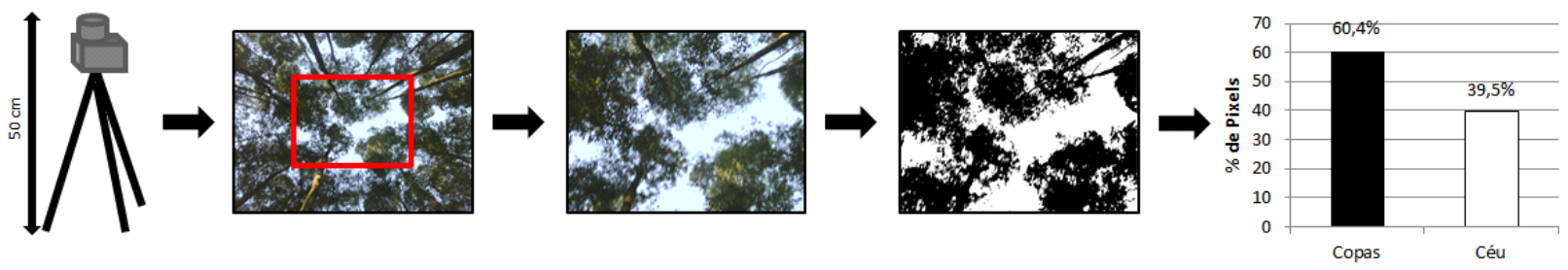

Figura 1 - Procedimentos para obtenção da cobertura foliar. Figure 1-Leaf cover proceedings.

Revista Árvore, Viçosa-MG, v.38, n.2, p.383-390, 2014

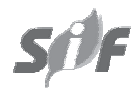


interceptação média para a Floresta Estacional Semidecidual (4,9\%) ao passo que E. cloeziana e $P$. caribea var. hondurensis apresentaram valores semelhantes (3,0 e 2,9\%, respectivamente).

Em algumas situações foram observados que a precipitação efetiva superou o volume acumulado de chuva na precipitação em aberto (Tabela 2). O maior número de eventos foi registrado para E. cloeziana, com variação de 2,8 a 57,5\% à mais que a precipitação em aberto. Para P. caribea var. hondurensis, esse comportamento foi notado apenas uma vez, e para a Floresta Estacional Semidecidual, foram três eventos sendo o maior deles igual a 75,6\%.

A caracterização da vegetação apontou uma maior cobertura foliar para a Floresta Estacional Semidecidual (81,8\%), seguida de E. cloeziana (79,3\%) е P. caribea var. hondurensis $(74,7 \%)$.

De modo a identificar o efeito linear das variáveis precipitação efetiva e interceptação em função da precipitação em aberto, essas informações foram submetidas à análise de regressão linear (Figura 2). Nas condições atuais de cobertura florestal na FLONA Ipanema, a precipitação efetiva e a precipitação em aberto apresentou alta correlação para E. cloeziana e P. caribea var. hondurensis, como indica o coeficiente de determinação $\left(\mathrm{R}^{2}\right)$. Para a correlação entre interceptação e precipitação em aberto, o maior $\mathrm{R}^{2}$ foi observado para E. cloeziana $(0,72)$.

A partir do coeficiente angular das equações de regressão da Figura 2, estimou-se a capacidade de retenção de água pelas copas entre as três formações florestais: P. caribea var. hondurensis apresentou a menor limitação de precipitação efetiva, com 0,74 mm, seguido por E. cloeziana e Floresta Estacional Semidecidual, ambos com 1,57mm. Para a interceptação, a Floresta Nacional Semidecidual apresentou uma maior retenção de água $(12,61 \mathrm{~mm})$, seguido pelo $P$. caribea var. hondurensis $(0,67 \mathrm{~mm})$ e E.cloeziana $(0,24 \mathrm{~mm})$.

\section{DISCUSSÃO}

O tipo de vegetação, seu estágio de regeneração e a área basal da mesma podem fornecer um indicativo do volume de água efetivamente precipitada na superfície da bacia hidrográfica. A cobertura vegetal, por meio da precipitação efetiva, tem influência na redistribuição da água de chuva, onde as copas das árvores formam um sistema de amortecimento e direcionamento das gotas que chegam ao solo de forma mais suave e menos impactante. O tipo de vegetação caracteriza a quantidade de gotas que cada folha pode reter e a densidade da mesma indica o volume retido na superfície de bacia hidrográfica (Tonello et al., 2004). Por outro lado, a

Tabela 2 - Eventos em que a precipitação efetiva superou a precipitação a céu aberto. FLONA Ipanema, Iperó, SP, 2009-2010.

Table 2 - Events of net precipitation $(P e)$ greater than the gross precipitation (P). FLONA Ipanema, Iperó, SP, 2009-2010.

\begin{tabular}{lccc}
\hline Formação florestal & $\mathrm{P}(\mathrm{mm})$ & $\mathrm{Pe}(\mathrm{mm})$ & $\%$ \\
\hline E. cloeziana & 2,9 & 3,0 & 2,8 \\
& 21,7 & 34,1 & 57,5 \\
& 3,6 & 3,9 & 7,7 \\
& 23,3 & 28,5 & 22,5 \\
& 15,3 & 17,0 & 11,4 \\
\hline Pinus sp. & 33,4 & 36,5 & 9,2 \\
\hline Floresta Est. Semidecidual & 19,6 & 34,4 & 75,6 \\
& 20,1 & 20,7 & 2,8 \\
& 25,1 & 25,9 & 3,1 \\
\hline
\end{tabular}

Tabela 1 - Precipitação em aberto (P), precipitação interna (Pi), escoamento pelo tronco (Et), precipitação efetiva (Pe) e interceptação (I) em diferentes formações florestais ao longo do período de monitoramento. FLONA Ipanema, Iperó, SP, 2009-2010.

Table 1 - Gross precipitation (P), throughfall (Pi), stemflow (Et), net precipitation (Pe) and loss interception (I) in different forests throughout the monitoring period. FLONA Ipanema, Iperó-SP, 2009-2010.

\begin{tabular}{|c|c|c|c|c|c|c|}
\hline \multirow[t]{2}{*}{ Partição chuvas } & \multicolumn{2}{|c|}{ E. cloeziana } & \multicolumn{2}{|c|}{ Pinus sp. } & \multicolumn{2}{|c|}{$\begin{array}{l}\text { Floresta estacional } \\
\text { semidecidual }\end{array}$} \\
\hline & $\mathrm{mm}$ & $\%$ & $\mathrm{~mm}$ & $\%$ & $\mathrm{~mm}$ & $\%$ \\
\hline $\mathrm{P}$ & 520,4 & 100,0 & 499,3 & 100,0 & 540,1 & 100,0 \\
\hline $\mathrm{Pi}$ & 443,4 & 85,2 & 419,5 & 84,0 & 411,8 & 76,2 \\
\hline $\mathrm{Et}$ & 5,1 & 1,0 & 5,1 & 1,0 & 5,4 & 1,0 \\
\hline $\mathrm{Pe}$ & 448,5 & 86,2 & 424,6 & 85,0 & 417,2 & 77,2 \\
\hline I & 71,9 & 13,8 & 74,7 & 15,0 & 122,9 & 22,8 \\
\hline
\end{tabular}




\section{Floresta Estacional Semidecidual}
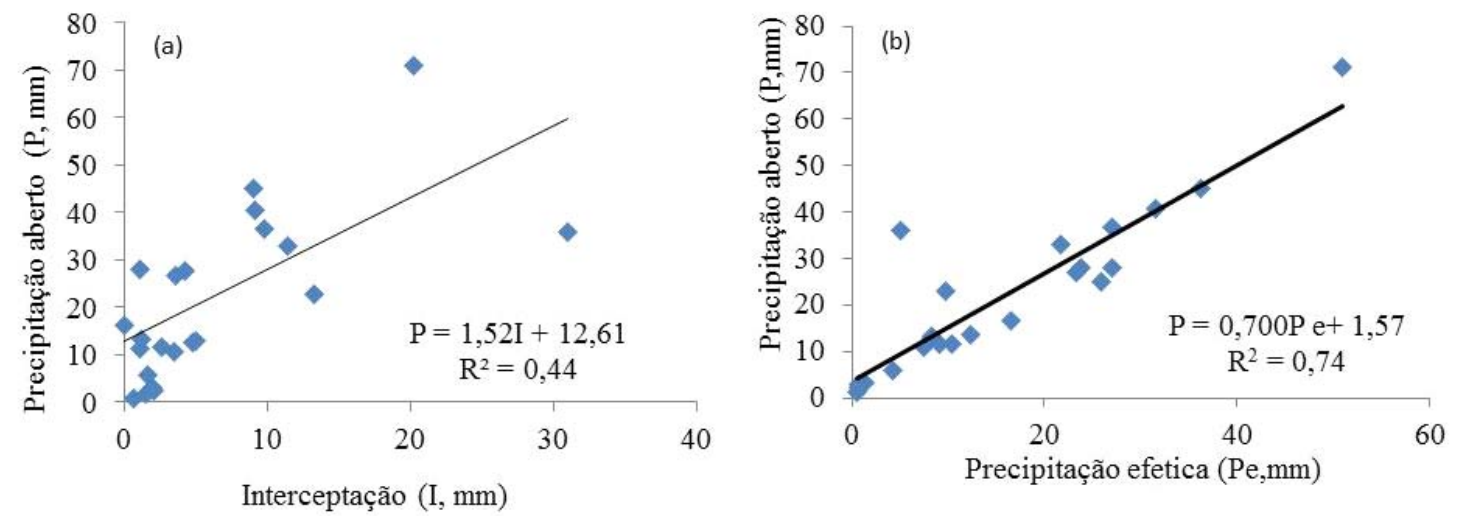

\section{Pinus sp.}
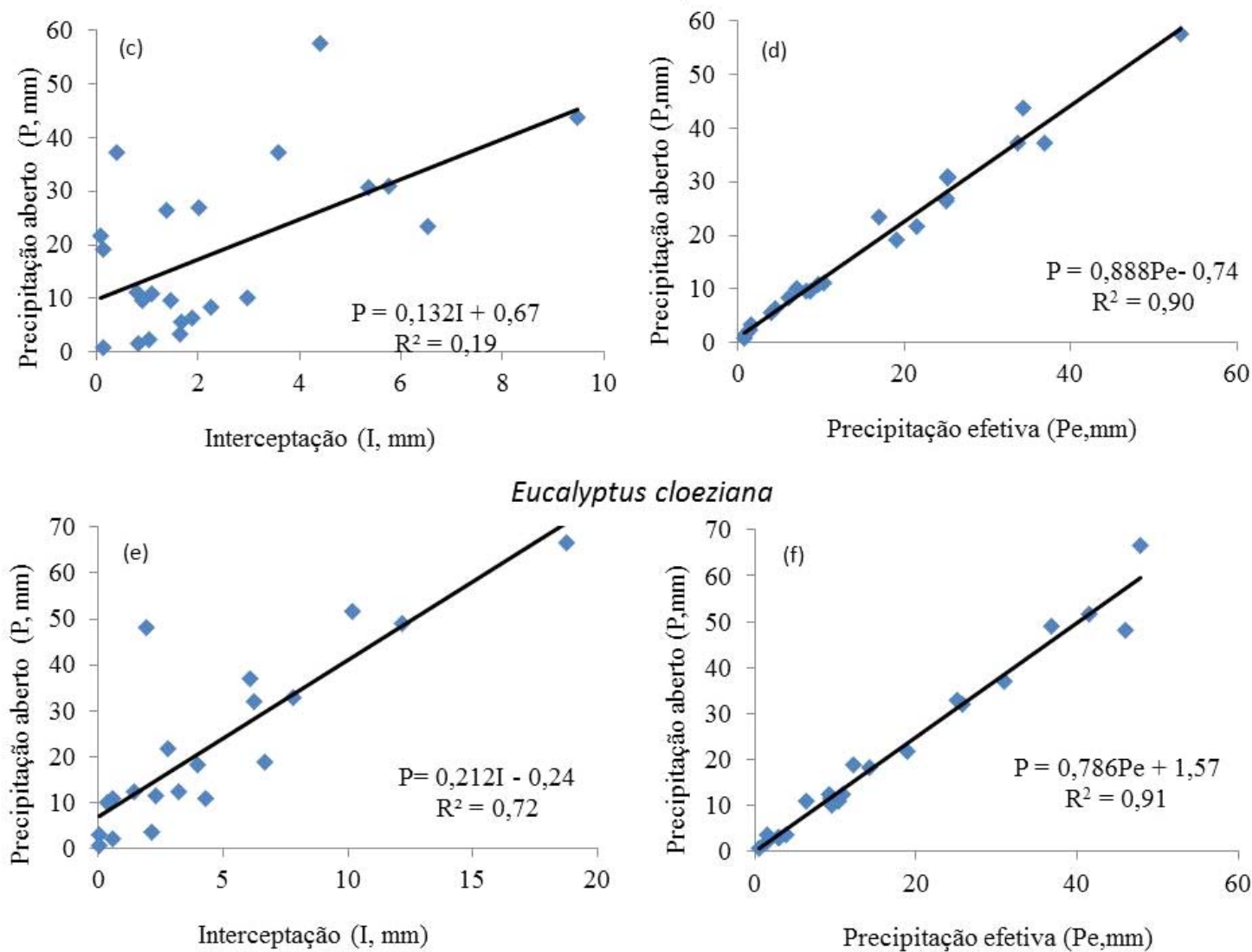

Figura 2 - Relação entre precipitação em aberto (P, mm) com interceptação (I, mm) e precipitação efetiva (Pe, mm) para Floresta Estacional Semidecidual (a, b), Pinus sp. (c, d) e Eucalyptus cloeziana (e, f), respectivamente. Floresta Nacional de Ipanema, Iperó, SP, 2009-2010.

Figure 2 - Relation between gross precipitation $(P, \mathrm{~mm})$ with interception $(I, \mathrm{~mm})$ and net precipitation $(P e, \mathrm{~mm})$ observed in a Semideciduous Forest $(a, b)$, Pinus sp. $(c, d)$ and Eucalyptus cloeziana $(e, f)$, respectively. Ipanema National Forest, Iperó, SP, 2009-2010.

Revista Árvore, Viçosa-MG, v.38, n.2, p.383-390, 2014 
porção de chuva que atinge o solo via precipitação interna e/ou escoamento superficial irá interferir na dinâmica do escoamento superficial e no processo de infiltração, de modo a proporcionar uma maior umidade para o mesmo e água disponível para utilização pelos vegetais.

Neste estudo, observou-se em alguns eventos que a precipitação interna foram superiores à precipitação em aberto (P), e embora o que em tese seria impossível de acontecer, tal fato já foi observado por diversos outros pesquisadores (KELLMAN e ROULET, 1990; MOURA et al., 2009). Isso pode ser justificado por algumas ocorrências como o entrelaçamento entre os galhos de diversas espécies contribuem para que o fluxo de escoamento ocorra por caminhos preferenciais, dando origem a pontos de gotejamento e áreas protegidas, que tendem a aumentar a contribuição de chuva em alguns coletores de precipitação interna e a diminuir em outros, respectivamente. A variabilidade também pode ocorrer, dentro e entre chuvas, à irregularidade da topografia, margem geométrica da floresta, tamanho e espaçamento das árvores (MOURA et al., 2009; NEAL et al., 1991) ou até mesmoa evaporação da água, principalmente nos pluviômetros situados em área aberta, com radiação incidente.

De fato, em todos os casos a precipitação interna foi a maior contribuinte para a precipitação efetiva. Contudo, a diferenciação na distribuição dos processos entre as formações florestais pode ser conseqüência da quantidade, diversidade e idade das espécies florestais, nível de inclusão de DAP, tipo de coletor de escoamento pelo tronco, arquitetura e forma de copa, estratificação das copas, filotaxia, orientação, tamanho, forma e tipo de folha, tipo de casca e irregularidades no tronco (OLIVEIRA JÚNIOR e DIAS, 2005).

Neste contexto, Lima (1976) observou em uma plantação de Pinus sp com 6 anos, valores de precipitação efetiva e interceptação equivalentes a 93,4\% e 6,6\% da precipitação em aberto, respectivamente, e, para Eucalyptus sp. com a mesma idade, de $87,8 \%$ para precipitação efetiva e $12,2 \%$ de interceptação. No caso de Eucalyptus sp, os valores apresentaram-se bem próximos aos observados neste estudo.

Oliveira Junior e Dias (2005), ao observar a precipitação efetiva em um fragmento secundário de Mata Atlântica em Viçosa-MG, verificaram que esta representou $81,7 \%$ da precipitação em aberto, destes,
$80 \%$ correspondeu à precipitação interna e 1,7\% ao escoamento pelo tronco, sendo assim, 18,3\% das chuvas foram interceptadas pelas copas.

A maior cobertura foliar observada na Florestal Estacional Semidecidual pode justificar a maior interceptação da chuva nesta formação florestal (Tabela 1) e maior capacidade de retenção da copa, comprovado pelo coeficiente angular da equação de regressão para este caso (Figura 2a). Além disso, dado o fato que povoamento de $P$. caribea var. hondurensis abrange menor cobertura foliar, há necessidade de uma menor precipitação em aberto para dar início ao processo de precipitação efetiva (Figura 2d). Outros fatores não mensurados neste estudo também podem estar relacionados com esta variável, como a conformidade e o ângulo de interseção das folhas, e a espessura e o grau de rugosidade da casca (OLIVEIRA JUNIOR e DIAS, 2005).

O alto coeficiente de determinação ( $\mathrm{R}^{2}$, Figura 2$)$ entre precipitação efetiva e a precipitação em aberto para E. cloeziana e P. caribea var. hondurensis pode ser atribuída à maior homogeneidade de espaçamentos e as idades equiâneas dessas formações florestais. Observa-se ainda que na Figura $2 b$ têm-se dois pontos mais distantes da reta, os quais podem ter proporcionado um menor $\mathrm{R}^{2}$ para as observações na Floresta Estacional Semidecidual. O menor coeficiente de determinação para a Figura 2c pode ter sido provocado pela concentração de chuva em algum coletor. Por sua vez, Arcova et al. (2003) observaram que a precipitação interna e o escoamento pelo tronco em um fragmento secundário de Floresta Atlântica apresentou elevada relação com a quantidade da precipitação no aberto, com o menor valor do coeficiente de determinação de $80 \%$.

\section{CONCLUSÕES}

O Eucalyptus cloeziana apresentou as maiores contribuições para a precipitação efetiva (86,2\%), seguido de Pinus caribea var. hondurensis (85,0\%) e Floresta Estacional Semidecidual (77,2\%), sendo encontrado nessa última o maior percentual de interceptação pela copa $(22,8 \%)$.

Para a precipitação efetiva não foram observadas diferenças significativas entre as três formações florestais, ao passo que para a interceptação, a Floresta Estacional Semidecidual diferiu das demais.

Revista Árvore, Viçosa-MG, v.38, n.2, p.383-390, 2014 


\section{AGRADECIMENTOS}

Aos técnicos Cícero Branco e Ivonir Piotrowski pelo auxílio nos trabalhos de campo. À equipe da Floresta Nacional de Ipanema pelo apoio e dedicação. Ao CNPq pela concessão da Bolsa de Iniciação Cientifica. Aos demais alunos da UFSCar, que auxiliaram no estudo.

\section{REFERÊNCIAS}

ALBUQUERQUE, G. B. Floresta Nacional de Ipanema: caracterização da vegetação em dois trechos distintos do Morro de Araçoiaba, Iperó (SP). 1999. 186p. Dissertação (Mestrado em Ciências Florestais) - Escola Superior de Agricultura Luiz de Queiroz, Piracicaba, 1999.

ARCOVA, F. C. S.; CICCO, V.; ROCHA, P. A. B. Precipitação efetiva e interceptação das chuvas por floresta de mata atlântica em uma microbacia experimental em Cunha, São Paulo. Revista Árvore, v.27, n.2, p.257-262, 2003.

BERTONI, J. C.; TUCCI, C. E. M. Precipitação. In: TUCCI, C. E. M. Hidrologia: ciência e aplicação. 2001. Porto Alegre, Universidade Federal do Rio grande do Sul, 2002. p.176-241.

CASTRO, P. S. et al. Interceptação da chuva por mata natural secundária na região de Viçosa, MG. Revista Árvore, v.7, n.1, p.76-89, 1983.

JIMÉNEZ, M. S. et al. Laurel forests in Tenerife, Canary Islands: the annual course of sap flow in Laurus trees and stand. Journal of

Hydrology, v.183, n.3/4, p.307-321, 1996.

KELLMAN, M.; ROULET, N. Stemflow and throughfall in a tropical dry forest. Earth Surface Processes Landforms, v.15, n.1, p.55-61, 1990.

KLASSEN, W.; LANKREIJER, H. J. M.; VEEN, A. W. L. Rainfall interception near a forest edge. Journal of Hydrology, n.185, p.349-361, 1996.

LEOPOLDO, P. R.; CONTE, M. L. Repartição da água de chuva em cobertura vegetal com características de cerradão. In: SIMPÓSIO BRASILEIRO DE HIDROLOGIA E RECURSOS HÍDRICOS E SIMPÓSIO INTERNACIONAL DE RECURSOS HÍDRICOS EM REGIÕES METROPOLITANAS, 6., 1985, São Paulo. Anais... São Paulo: ABRH, 1985. v.3. p.212-220.
LIMA, W. P. Hidrologia de plantações de eucaliptos. In: LIMA, W.P. Impacto ambiental do eucalipto. São Paulo: Universidade de São Paulo, 1993. p.51-137.

LIMA, W. P. Interceptação da chuva por povoamentos de eucaliptos e de pinheiros. IPEF, v.13, p.75-90, 1976.

MONTE, M.A.; REIS, M.G.F.; REIS, G.G.; LEITE, H.G.; STOCKS, J.J. Métodos indiretos de estimação da cobertura de dossel em povoamentos de clone de eucalipto. Pesq. Agropec. Bras., Brasília, v.42, n.6, p.769-775, jun. 2007.

MOURA, A. E. S. S. et al. Interceptação das chuvas em um fragmento de floresta da Mata Atlântica na Bacia do Prata, Recife, PE. Revista Árvore, v.33 n.3, p.461-469, 2009.

NEAL, C. et al. Hydrological impacts of hardwood plantation in lowland Britain: preliminary findings on interception at a forest edge, Black Wood, Hampshire, Southern England. Journal of Hydrology, v.127, n.1/4, p.349-65, 1991.

OLIVEIRA JUNIOR, J. C.; DIAS, H. C. T. Precipitação efetiva em fragmento secundário da Mata Atlantica. Revista Árvore, v.29, n.1, p.6-15, 2005.

RADAMBRASIL - MINISTÉRIO DAS MINAS E ENERGIA/DEPARTAMENTO NACIONALDE PRODUÇÃO MINERAL. Projeto Radambrasil: Levantamento de Recursos Naturais. Folha Rio de Janeiro. Rio de Janeiro: DNPM/ Projeto RADAMBRASIL, 1984.

REGALADO, L. B. Composição e distribuição de aves passeriformes em uma parcela de mata do Morro de Araçoiaba (Floresta Nacional de Ipanema, Iperó/ SP) utilizando um sistema de informação geográfica. 1999. 118p. Dissertação (Mestrado em Engenharia Ambiental) - Escola de Engenharia de São Carlos, São Carlos, 1999.

SOUZA, P. C.; MARTOS, H. L. Estudo do uso público e análise ambiental das trilhas em uma unidade de conservação de uso sustentável: Floresta Nacional de Ipanema, Iperó - SP. Revista Árvore, v. 32, n. 1, p. 91-100, Feb. 2008.

TONELLO, K. C. et al. Precipitação efetiva em plantio de pinus. Revista da Madeira, v.38, p. 118-121, 2004. 